\title{
Healthcare Personnel Attire in Non-Operating-Room Settings
}

\author{
Gonzalo Bearman, MD, MPH; ${ }^{1}$ Kristina Bryant, MD; ${ }^{2}$ Surbhi Leekha, MBBS, MPH; ${ }^{3}$ Jeanmarie Mayer, MD; ${ }^{4}$ \\ L. Silvia Munoz-Price, MD; ${ }^{5}$ Rekha Murthy, MD; ${ }^{6}$ Tara Palmore, $M D ;{ }^{7}$ \\ Mark E. Rupp, MD; Joshua White, MD $^{9}$
}

\begin{abstract}
Healthcare personnel (HCP) attire is an aspect of the medical profession steeped in culture and tradition. The role of attire in crosstransmission remains poorly established, and until more definitive information exists priority should be placed on evidence-based measures to prevent healthcare-associated infections (HAIs). This article aims to provide general guidance to the medical community regarding HCP attire outside the operating room. In addition to the initial guidance statement, the article has 3 major components: (1) a review and interpretation of the medical literature regarding (a) perceptions of HCP attire (from both HCP and patients) and (b) evidence for contamination of attire and its potential contribution to cross-transmission; (2) a review of hospital policies related to HCP attire, as submitted by members of the Society for Healthcare Epidemiology of America (SHEA) Guidelines Committee; and (3) a survey of SHEA and SHEA Research Network members that assessed both institutional HCP attire policies and perceptions of HCP attire in the crosstransmission of pathogens. Recommendations for HCP attire should attempt to balance professional appearance, comfort, and practicality with the potential role of apparel in the cross-transmission of pathogens. Although the optimal choice of HCP attire for inpatient care remains undefined, we provide recommendations on the use of white coats, neckties, footwear, the bare-below-the-elbows strategy, and laundering. Institutions considering these optional measures should introduce them with a well-organized communication and education effort directed at both HCP and patients. Appropriately designed studies are needed to better define the relationship between HCP attire and HAIs.
\end{abstract}

Infect Control Hosp Epidemiol 2014;35(2):107-121

Healthcare personnel (HCP) attire is an aspect of the medical profession steeped in culture and tradition. From Hippocrates's admonition that physicians' dress is essential to their dignity, to the advent of nurses' uniforms under the leadership of Florence Nightingale, to the white coat ceremonies that continue to this day in medical schools, HCP apparel and appearance is associated with significant symbolism and professionalism. Recent years, however, have seen a rising awareness of the potential role of fomites in the hospital environment in the transmission of healthcare-associated microorganisms. Although studies have demonstrated contamination of HCP apparel with potential pathogens, the role of clothing in transmission of these microorganisms to patients has not been established. The paucity of evidence has stymied efforts to produce generalizable, evidence-based recommendations, resulting in widely disparate practices and requirements that vary by country, region, culture, facility, and discipline. This document is an effort to analyze the available data, issue reasonable recommendations, and describe the needs for future studies to close the gaps in knowledge on HCP attire.

\section{INTENDED USE}

This document is intended to help acute care hospitals develop or modify policies related to HCP attire. It does not address attire in the operating room $(\mathrm{OR})$, perioperative areas, or other procedural areas and is not intended to guide $\mathrm{HCP}$ attire in those settings or in healthcare facilities other than acute care hospitals.

\section{SOCIETY FOR HEALTHCARE EPIDEMIOLOGY OF AMERICA（SHEA）WRITING GROUP}

The writing group consists of volunteers among members of the SHEA Guidelines Committee, including those with research expertise on this topic.

Affiliations: 1. Virginia Commonwealth University, Richmond, Virginia; 2. University of Louisville, Louisville, Kentucky; 3. Department of Epidemiology and Public Health, University of Maryland, Baltimore, Maryland; 4. Division of Infectious Diseases, Department of Internal Medicine, University of Utah School of Medicine, Salt Lake City, Utah; 5. Departments of Medicine and Public Health Sciences, University of Miami, Miami, Florida; 6. Department of Hospital Epidemiology, Cedars-Sinai Medical Center, Los Angeles, California; 7. National Institutes of Health Clinical Center, Bethesda, Maryland; 8. University of Nebraska Medical Center, Omaha, Nebraska; 9. Virginia Commonwealth University, Richmond, Virginia.

Received November 21, 2013; accepted November 25, 2013; electronically published January 16, 2014.

(C) 2014 by The Society for Healthcare Epidemiology of America. All rights reserved. 0899-823X/2014/3502-0001\$15.00. DOI: $10.1086 / 675066$ 


\section{KEY AREAS ADDRESSED}

We evaluated and summarized the literature around 2 aspects of HCP attire (details are provided in "Methods"):

I. Perception of both patients and HCP regarding HCP attire in relation to professionalism and potential risk for transmission of microorganisms.

II. Evidence for contamination of HCP attire and the potential for HCP attire to contribute to the transmission of pathogenic microorganisms in hospitals.

In addition, we performed a survey of the SHEA membership and SHEA Research Network to learn more about the policies related to HCP attire that are currently in place in members' institutions.

\section{GUIDANCE AND RECOMMENDATION} FORMA T

Because this topic lacks the level of evidence required for a more formal guideline using the GRADE system, no grading of the evidence level is provided for individual recommendations. Each guidance statement is based on synthesis of limited evidence, theoretical rationale, practical considerations, a survey of SHEA membership and the SHEA Research Network, author opinion, and consideration of potential harm where applicable. An accompanying rationale is listed alongside each recommendation.

\section{GUIDANCE STATEMENT}

There is a paucity of data on the optimal approach to HCP attire in clinical, nonsurgical areas. Attire choices should attempt to balance professional appearance, comfort, and practicality with the potential role of apparel in the cross-transmission of pathogens resulting in healthcare-associated infections (HAIs).

As the SHEA workgroup on HCP attire, we recommend the following:

I. Appropriately designed studies should be funded and performed to better define the relationship between HCP attire and HAIs.

II. Until such studies are reported, priority should be placed on evidence-based measures to prevent HAIs (eg, hand hygiene, appropriate device insertion and care, isolation of patients with communicable diseases, environmental disinfection).

III. The following specific approaches to practice related to HCP attire may be considered by individual facilities; however, in institutions that wish to pursue these practices, measures should be voluntary and accompanied by a well-organized communication and education effort directed at both HCP and patients.

A. "Bare below the elbows" (BBE): This article defines BBE as HCP's wearing of short sleeves, no wristwatch, no jewelry, and no ties during clinical practice. Facilities may consider adoption of a BBE approach to inpatient care as an infection prevention adjunct, although the optimal choice of alternate attire, such as scrub uniforms or other short-sleeved personal attire, remains undefined.

1. Rationale: While the incremental infection prevention impact of a BBE approach to inpatient care is unknown, this practice is supported by biological plausibility and studies in laboratory and clinical settings and is unlikely to cause harm.

B. White coats: Facilities that mandate or strongly recommend use of a white coat for professional appearance should institute one or more of the following measures: 1. HCP engaged in direct patient care (including house staff and students) should possess 2 or more white coats and have access to a convenient and economical means to launder white coats (eg, institution-provided on-site laundering at no cost or low cost).

i. Rationale: These practical considerations may help achieve the desired professional appearance yet allow for HCP to maintain a higher frequency of laundering of white coats.

2. Institutions should provide coat hooks that would allow HCP to remove their white coat (or other longsleeved outerwear) prior to contact with patients or the patient's immediate environment.

i. Rationale: This practical consideration may help achieve the desired professional appearance yet limit patients' direct contact with potentially contaminated attire and avoid potential contamination of white coats that may otherwise be hung on inappropriate objects in the hospital environment.

C. Other HCP apparel: On the basis of the current evidence, we cannot recommend limiting the use of other specific items of HCP apparel (such as neckties).

1. Rationale: The role played by neckties and other specific items of HCP apparel in the horizontal transmission of pathogens remains undetermined. If neckties are worn, they should be secured by a white coat or other means to prevent them from coming into direct contact with the patient or near-patient environment.

\section{Laundering:}

1. Frequency: Optimally, any apparel worn at the bedside that comes into contact with the patient or patient environment should be laundered after daily use. In our opinion, white coats worn during patient care should be laundered no less frequently than once a week and when visibly soiled.

i. Rationale: White coats worn by HCP who care for very few patients or by HCP who are infrequently involved in direct patient care activities may need to be laundered less frequently than white coats 
worn by HCP involved with more frequent patient care. At least weekly laundering may help achieve a balance between microbial burden, visible cleanliness, professional appearance, and resource utilization.

2. Home laundering: Whether HCP attire for nonsurgical settings should be laundered at home or professionally remains unclear. If laundered at home, a hot-water wash cycle (ideally with bleach) followed by a cycle in the dryer is preferable.

i. Rationale: A combination of washing at higher temperatures and tumble drying or ironing has been associated with elimination of both pathogenic gram-positive and gram-negative bacteria.

E. HCP footwear: All footwear should have closed toes, low heels, and nonskid soles.

1. Rationale: The choice of HCP footwear should be driven by a concern for HCP safety and should decrease the risk of exposure to blood or other potentially infectious material, sharps injuries, and slipping.

F. Identification: Name tags or identification badges should be clearly visible on all HCP attire for identification purposes.

1. Rationale: Name tags have consistently been identified as a preferred component of HCP attire by patients in several studies, are associated with professional appearance, and are an important component of a hospital's security system.

IV. Shared equipment, including stethoscopes, should be cleaned between patients.

$\mathrm{V}$. No guidance can be offered in general regarding prohibiting items like lanyards, identification tags and sleeves, cell phones, pagers, and jewelry, but those items that come into direct contact with the patient or environment should be disinfected, replaced, or eliminated.

\section{METHODS}

Using PubMed/Medline, between the months of January and May 2013 we searched the English literature for articles pertaining to HCP attire in clinical settings focusing on areas outside the OR. We included all studies dealing with bacterial contamination and laundering of HCP attire, patients' and providers' perceptions based on the type of attire, and/or HCP footwear.

Additionally, we reviewed and compared hospital policies related to $\mathrm{HCP}$ attire from 7 large teaching hospitals, as submitted by members of the SHEA Guidelines Committee. Finally, between February and May 2013 we sent out a survey to all SHEA members to assess their institutional HCP attire policies (if any) and to determine their perceptions of HCP attire as a vehicle for potential transmission of pathogens.

\section{RESULTS}

\section{Patients' Perceptions of HCP Attire}

We identified 26 studies (published from 1990 onward) that examined patients' perceptions of HCP attire ${ }^{1-26}$ (Table 1). Most (23/26) studies surveyed patient preference for different types of HCP attire ${ }^{1-6,8-18,20-25}$ using either pictures of models in various dress styles ${ }^{3,4,7-9,15-18,20,22-24}$ or descriptions of attire. ${ }^{1,5,11,14,21,25}$ Four studies ${ }^{6,10,12,13}$ asked patients to assess the attire of their actual physicians. Attire descriptions and terminology varied among studies (eg, "formal," "business," "smart," "suit and tie," and "dress") and will be referred to hereafter as "formal attire." We use "casual attire" to refer to anything other than formal attire.

A. Formal attire and white coats: Most of the studies using pictures and models of HCP attire indicated patient preference for formal attire, which was favored over both scrubs $^{1,3,7,9,18,22}$ and casual attire. ${ }^{7,9,15,16,19,22}$ However, several other studies revealed that physician attire was unlikely to influence patients' levels of comfort, ${ }^{4,20}$ satisfaction, trust, or confidence in physicians' abilities, ${ }^{2,49,19,20,25}$ even if patients previously had expressed a preference for one type of attire. ${ }^{4,9,20,25}$

Fifteen studies addressed white coats. ${ }^{1,4,7-9,11-17,20-22}$ In 10 of these studies, patients preferred that physicians wear white coats, ${ }^{1,7-10,12,15-17}$ and in 1 study patients reported feeling more confident in those physicians. ${ }^{8}$ Similarly, 2 studies showed a significant association between the presence of a white coat, especially on a female physician, and patients' trust and willingness to share sensitive information. ${ }^{22}$ Patients also indicated less comfort in dealing with an informally dressed physician, ${ }^{16}$ describing a shirt and a tie as the most professional and desirable attire for physicians $s^{23-25}$ in addition to an overall well-groomed appearance. ${ }^{5,15}$ Moreover, the following items were deemed as inappropriate or undesirable: jeans, ${ }^{5,14}$ shorts, ${ }^{15}$ clogs, ${ }^{14,15}$ and open-toed sandals. ${ }^{15}$ In the remaining 5 studies, patients showed no clear predilection for one dress style over another or did not consider a white coat either necessary or expected. ${ }^{4,11,13,20,21}$

Five studies assessed patient satisfaction, confidence, or trust on the basis of their treating physicians' dress, ${ }^{2,6,10,12,13}$ showing little response variations regardless of apparel. A survey of patients seen by obstetricians/gynecologists who were randomly assigned formal attire, casual attire, or scrubs found high satisfaction with physicians regardless of the group allocation. ${ }^{6}$ Similarly, in a before-and-after trial, emergency department (ED) physicians were asked to wear formal attire with a white coat one week followed by scrubs the subsequent week. Using a visual analog scale, patients rated their physician's appearance, professionalism, and satisfaction equally regardless of the week of observation. ${ }^{13}$ Another ED study found no difference in 


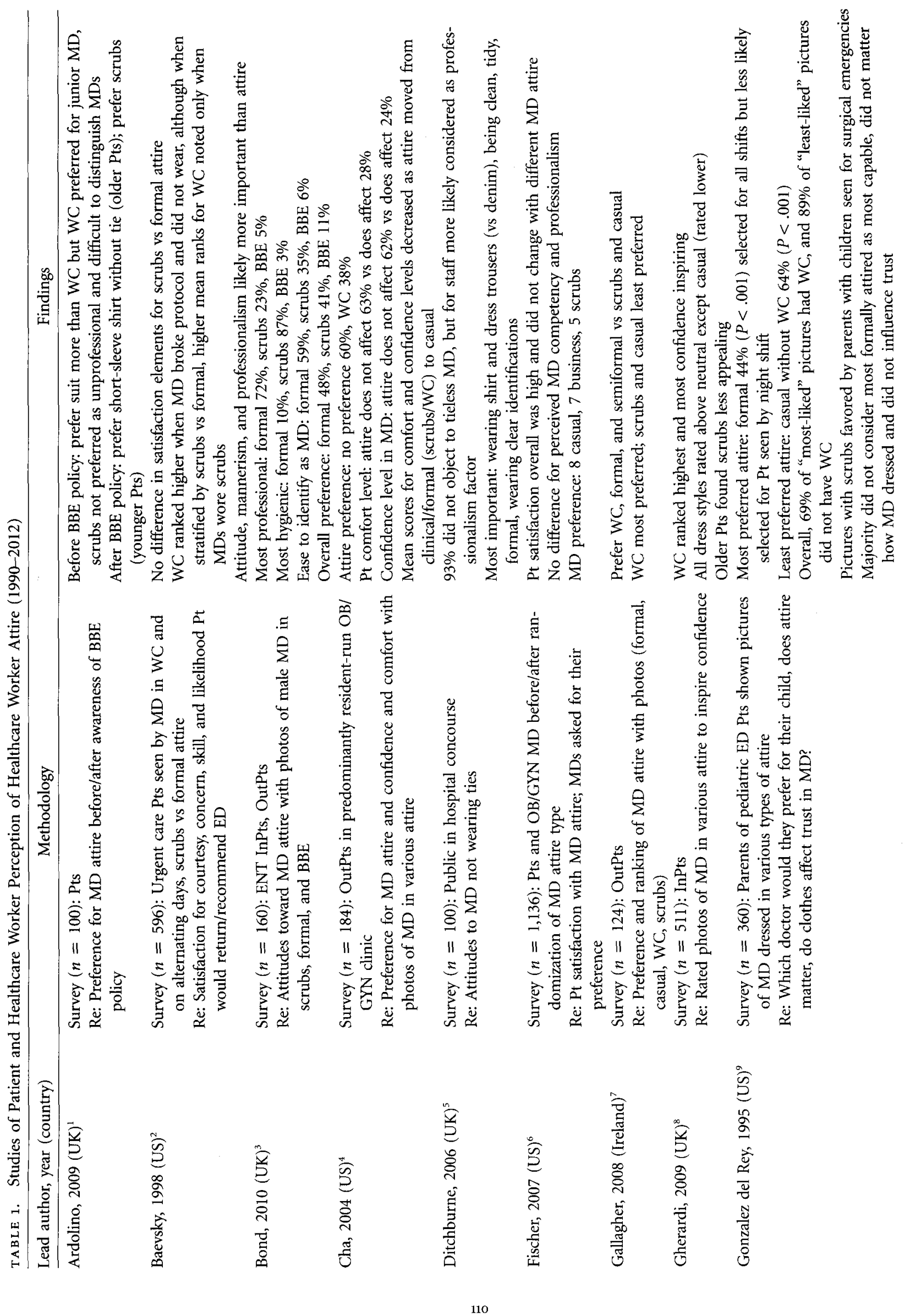




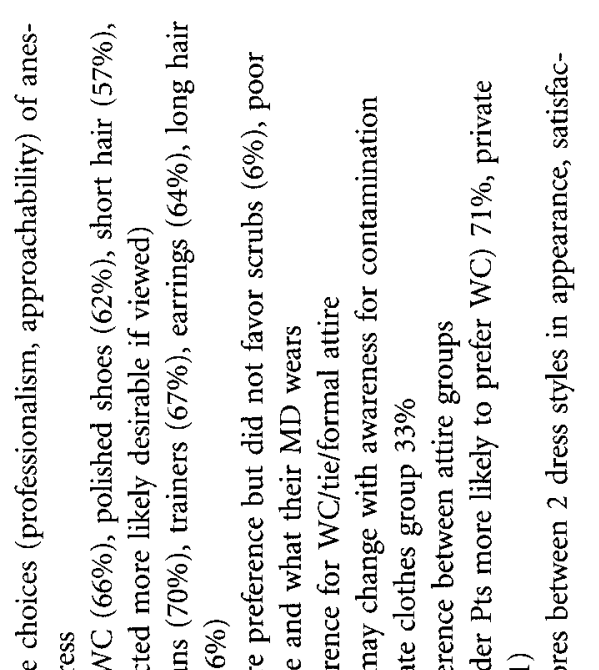

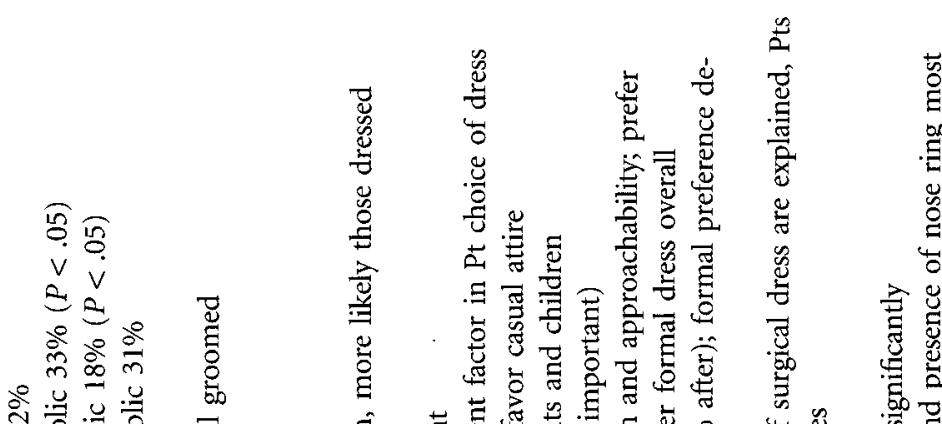

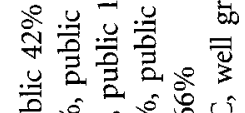

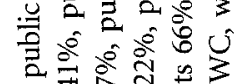

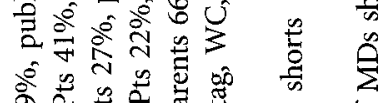

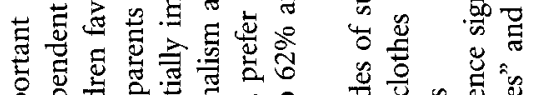

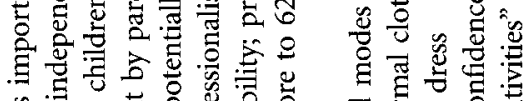

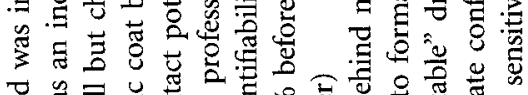

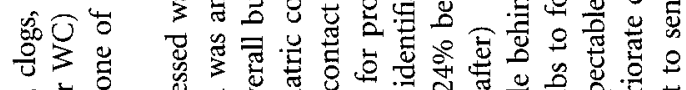

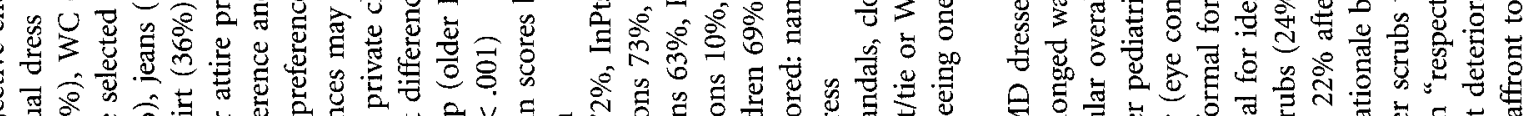

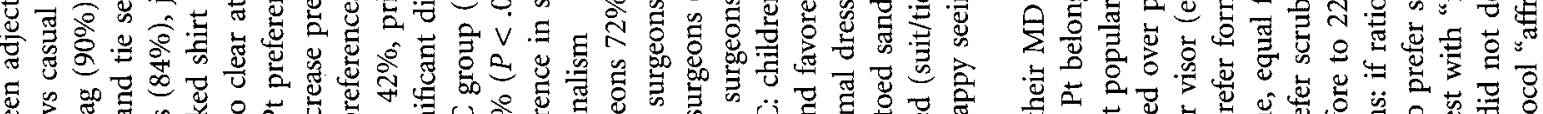

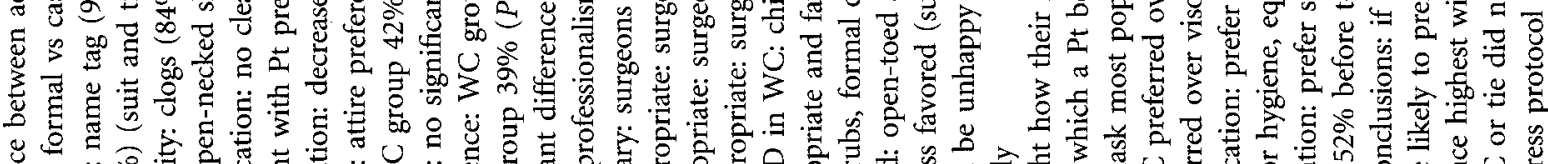

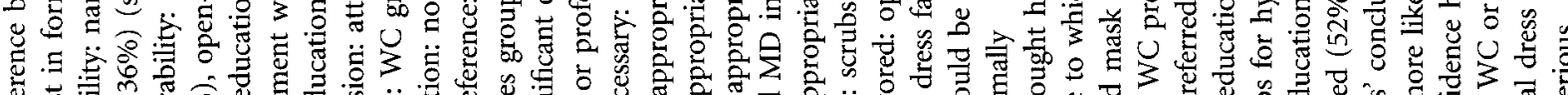

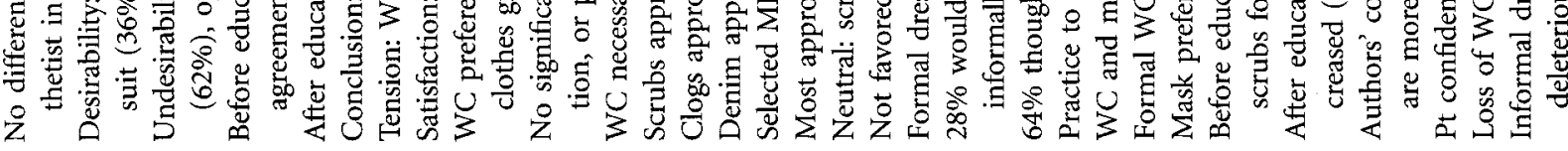

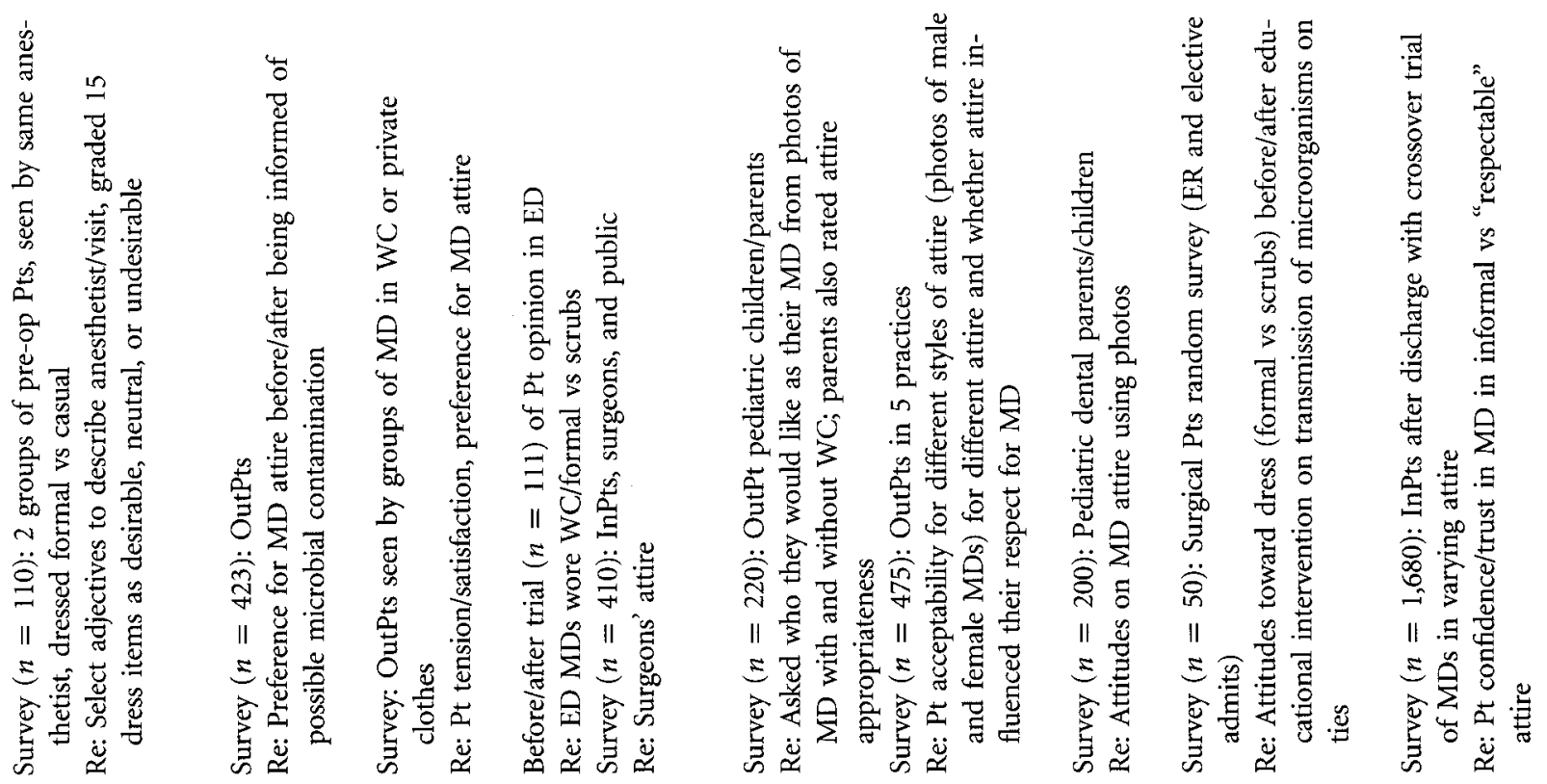

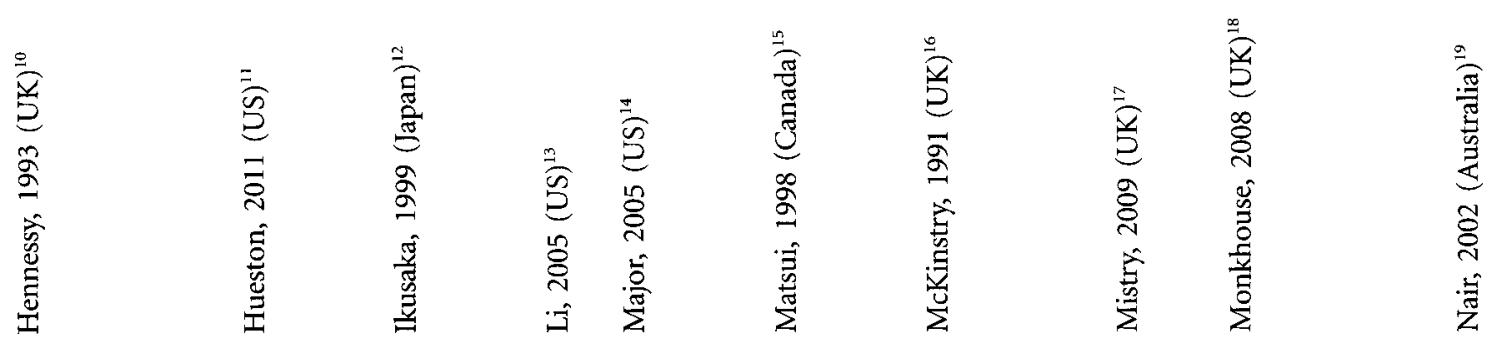




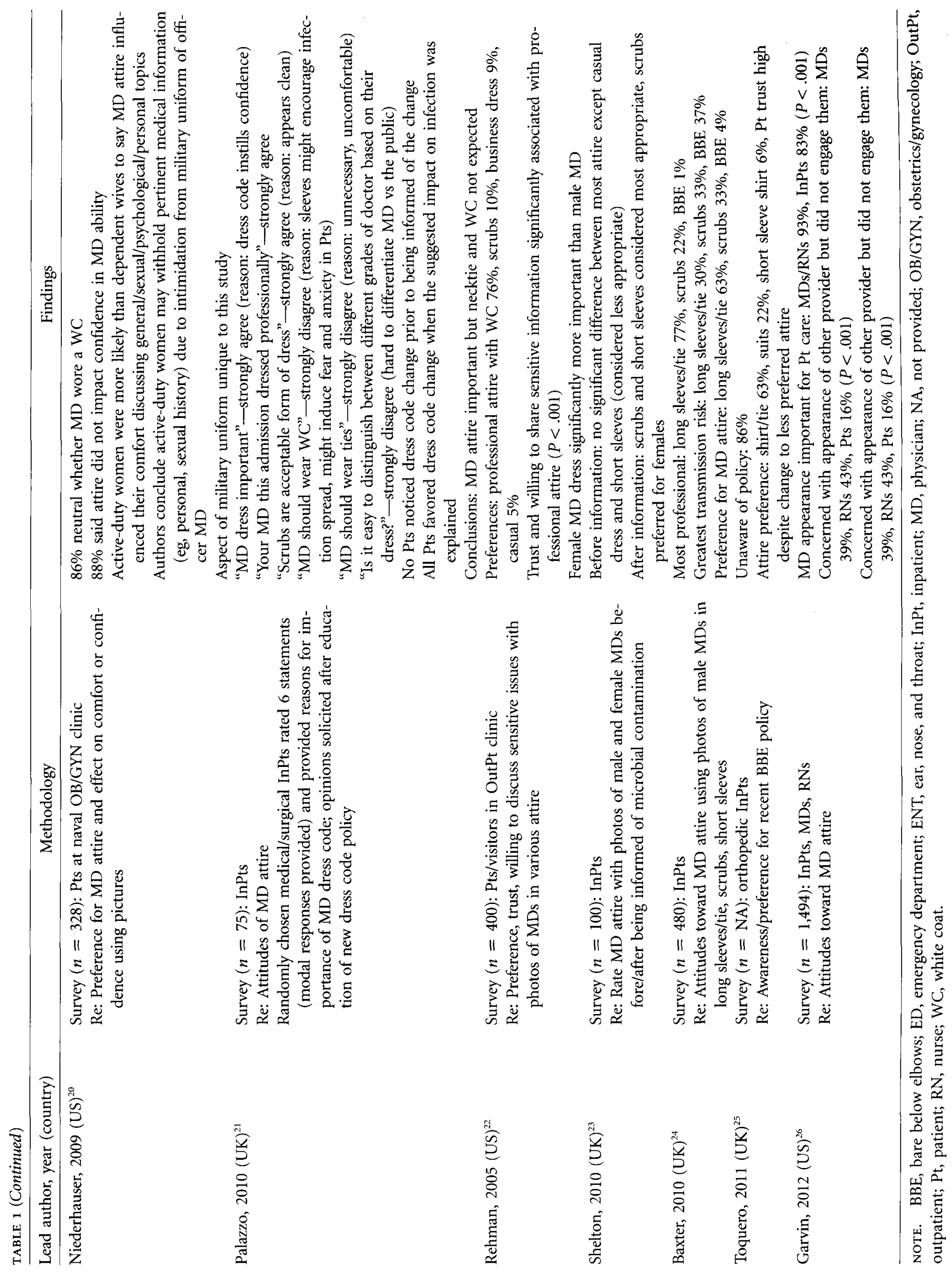


patients' satisfaction with the care provided when their physicians wore white coats combined with either scrubs or formal attire. ${ }^{2}$ Similarly, 2 groups of patients who received preoperative care by the same anesthesiologist wearing either formal attire for one group of patients or casual attire for the other found no differences in patient satisfaction between the groups. ${ }^{10}$ In contrast, one crossover trial involving physicians dressed in "respectable" or formal versus "retro" or casual attire found that patient confidence and trust were higher with the respectabledress protocol. ${ }^{19}$ Another study evaluating the attire of patients' treating physicians indicated preference for polished shoes and short hair for men, with jeans, clogs, trainers, and earrings on men being rated as undesirable. ${ }^{10}$ A survey among Japanese outpatients indicated a preference for white coats but no significant difference in satisfaction levels based on attire when presented with physicians wearing white coats or "noninstitutional clothes." ${ }^{12}$

B. BBE: Preference for BBE was assessed in 6 studies originating in the United Kingdom following implementation of the nationwide BBE policy ${ }^{1,3,23-25}$ and in 1 US study. ${ }^{11}$ In these 7 reports, patients did not prefer short sleeves. After informing patients of the BBE policy, older patients were more likely to prefer short-sleeved shirts without ties, while younger patients favored scrubs. ${ }^{1}$ After providing information about the potential for cross-contamination from shirt sleeve cuffs and neckties, responses changed from a preference for formal or long-sleeved attire to a preference for short sleeves or scrubs. ${ }^{11,18,23}$ In addition, Shelton et $\mathrm{al}^{23}$ also found an association between physician gender and BBE attire: after a statement informing the participants of the potential cross-transmission of microorganisms by attire, patients preferred scrubs for female physicians but did not differentiate between scrubs and short-sleeved shirts for male physicians.

C. Ties: Neckties were specifically addressed in several studies from the United Kingdom. ${ }^{5,21,24}$ In one study, patients reported that attire was important but that neckties were not expected. ${ }^{21}$ Similarly, in a survey among individuals in the public concourse of a hospital, $93 \%$ had no objection to male physicians not wearing ties. ${ }^{5}$ None of these studies evaluated neckties in the context of patients' perceptions of infection prevention.

D. Laundering of clothes: In one study, patients identified "daily laundered clothing" as the single most important aspect of physicians' appearance. ${ }^{8}$

E. Other factors: Several additional variables may influence patient preference for physician attire, including age of either the patient or the managing physician, gender of the practitioner, time of day, setting, and the attire patients are accustomed to seeing. In Japan, older patients were more likely to prefer white coats. ${ }^{12}$ Similarly, older patients in England found scrubs less appealing than did younger patients. ${ }^{8}$ Pediatric dental patients were more likely than their parents to favor casual attire. ${ }^{17}$ Patients preferred formal attire for senior consultants but thought that junior physicians should be less formal. ${ }^{1}$ Patients identified female physicians' attire as more important than the attire worn by male physicians. ${ }^{22}$ Formal attire was less desirable by patients seen during the night shift. ${ }^{9}$ Parents of children being seen in the ED favored surgical scrubs. Additionally, 2 trials evaluated attire preference on the basis of what patients often see their HCP wearing. In one trial, patients accustomed to seeing their anesthesiologist in a suit were more likely to find suits and ties desirable. ${ }^{10}$ Similarly, the practice to which a patient belonged was found to be an independent factor in the patient's choice of preferred attire; ${ }^{16}$ however, another study found poor agreement between patient preferences and their physicians' typical attire. $^{11}$

In summary, patients express preferences for certain types of attire, with most studies indicating a predilection for formal attire, including a white coat, but these partialities had a limited overall impact on patient satisfaction and confidence in practitioners. This is particularly true in trials that evaluated the effect of attire on patient satisfaction in real-world settings. Patients generally do not perceive white coats, formal attire, or neckties as posing infection risks; however, when informed of potential risks associated with certain types of attire, patients appear willing to change their preferences for physician attire. ${ }^{11,18}$

\section{HCP Perceptions regarding Attire}

Few studies evaluated HCP preferences with regard to attire. ${ }^{5,6,14,26}$ While most studies addressed specific elements of HCP attire, one looked at the overall importance of attire and found that $93 \%$ of physicians and nurses versus $83 \%$ of patients thought that physician appearance was important for patient care $(P<.001) .^{26}$

A. White coats: In a survey exploring perceptions of surgeons' apparel performed among surgeons themselves, inpatients, and the nonhospitalized public, all 3 groups were equally likely to consider a white coat necessary and blue jeans inappropriate. Surgeons were more prone to consider scrubs and clogs appropriate. ${ }^{14}$ In another survey of 15 obstetricians/gynecologists, 8 preferred casual attire, while 7 preferred formal attire. ${ }^{\circ}$ Three studies assessed $\mathrm{HCP}$ alongside patient perception of infection risk or lack of hygiene associated with white coats, formal attire, or neckties, ${ }^{3,24,26}$ with one finding that HCP were more likely than patients to consider white coats unhygienic. ${ }^{26}$

B. Ties: In a survey performed in a public concourse of a UK hospital, HCP were more likely than non-HCP to prefer physicians' wearing of neckties for reasons of professionalism. $^{5}$

C. Laundering of clothes: A recent survey showed that nonsurgical providers preferentially (and without prompting) 
laundered their scrubs every $1.7 \pm 0.1$ days (mean \pm standard error) compared with white coats, which were laundered every $12.4 \pm 1.1$ days $(P<.001)$; however, the reasons for this divergent behavior remain unclear. $^{27}$

\section{Studies of Microbial Contamination of Apparel in Clinical and Laboratory Settings}

No clinical studies have demonstrated cross-transmission of healthcare-associated pathogens from a HCP to a patient via apparel; however, a number of small prospective trials have demonstrated the contamination of HCP apparel with a variety of pathogens (Table 2). ${ }^{5,28-37}$

A. White coats/uniforms: The 5 studies we evaluated indicate that physician white coats and nursing uniforms may serve as potential sources of colonization and cross-transmission. Several studies described contamination of apparel with Staphylococcus aureus in the range of 5\% to $29 \%{ }^{30,33-35,38}$ Although gram-negative bacilli have also been identified, these were for the most part of low pathogenicity ${ }^{30,35}$ however, actual pathogens, such as Acinetobacter species, Enterobacteriaceae, and Pseudomonas species, have been reported..$^{38}$

A number of factors were found to influence the magnitude of contamination of white coats and uniforms. First, the degree of contamination was correlated with more frequent usage of the coat,$^{35}$ recent work in the inpatient setting, ${ }^{34}$ and sampling certain parts of the uniform. Higher bacterial loads were found on areas of clothing that were more likely to come into contact with the patient, such as the sleeve. ${ }^{35}$ Additionally, the burden of resistant pathogens on apparel was inversely correlated with the frequency of lab coat change. ${ }^{38}$ Apparel contamination with pathogenic microorganisms increased over the course of a single patient care shift. Burden et $\mathrm{al}^{28}$ demonstrated that clean uniforms become contaminated within only a few hours of donning them. Similarly, a study testing nurses' uniforms at both the beginning and the end of their shifts described an increase in the number of uniforms contaminated with one or more microorganisms from $39 \%$ to $54 \%$, respectively. The proportion of uniforms contaminated with vancomycin-resistant enterococci (VRE), methicillin-resistant $S$. aureus (MRSA), and Clostridium difficile was also noted to increase with shift work. ${ }^{33}$

In the first report of a positive correlation between contamination of hands and contamination of white coats, Munoz-Price et $\mathrm{al}^{39}$ cultured the hands, scrubs, and white coats of intensive care unit staff. The majority of bacteria isolated from hands were skin commensals, but HCP were also found to have contamination of hands, scrubs, and white coats with potentially pathogenic bacteria, including S. aureus, Enterococcus species, and Acinetobacter baumannii. Among dominant hands, $17 \%$ of 119 hands were contaminated with one of these species, and staff members with contaminated hands were more likely to wear a white coat contaminated with the same pathogen. This association was not observed with scrubs.

B. BBE: Two observational trials evaluated the bacterial contamination of HCP's hands on the basis of BBE attire versus controls, finding no difference in total bacterial counts or in the number of clinically significant pathogens. ${ }^{40,41}$ In contrast, Farrington et $\mathrm{al}^{42}$ using a fluorescent method, examined the efficacy of an alcohol hand wash among BBE providers versus controls. The authors found decreased efficacy of hand hygiene at the wrist level in the non-BBE group, suggesting that the BBE approach may improve wrist disinfection during hand washing.

The United Kingdom has adopted a BBE approach, on the basis of the theory that it will limit patient contact with contaminated HCP apparel and to promote better hand and wrist hygiene. However, a randomized trial comparing bacterial contamination of white coats against BBE found no difference in total bacterial or MRSA counts (on either the apparel itself or from the volar surface of the wrist) at the end of an 8-hour workday. ${ }^{28}$

C. Scrubs: The use of antimicrobial-impregnated scrubs has been evaluated as a possible solution to uniform contamination. In a prospective, randomized crossover trial of $30 \mathrm{HCP}$ in the intensive care unit setting, ${ }^{36}$ when compared with standard scrubs, antimicrobial-impregnated scrubs were associated with a 4-7 mean log reduction in surface MRSA burden, although there was no difference in MRSA load on HCP hands or in the number of VRE or gram-negative bacilli cultured from the scrubs. The study did not assess the HAI impact of the antimicrobial scrubs.

D. Ties: Several studies indicated that neckties may be colonized with pathogenic bacteria, including $S$. aureus. Lopez et a $\mathbf{l}^{31}$ reported a significantly higher bacterial burden on neckties than on the front shirt pocket of the same subject. In 3 studies, up to $32 \%$ of physician neckties grew S. aureus. ${ }^{5,31,37}$ Steinlechner et a ${ }^{37}$ identified additional potential pathogens and commensals from necktie cultures, including Bacillus species and gram-negative bacilli. Two reports found that up to $70 \%$ of physicians admitted having never cleaned their ties. ${ }^{5,31}$

E. Laundering of clothes: Numerous articles published during the past 25 years describe the efficacy of laundering hospital linens and HCP clothing, ${ }^{44}$ but most investigations of the laundering of HCP attire have employed in vitro experimental designs that may or may not reflect real-life conditions. A 2006 study $^{45}$ demonstrated that while clothes lost their burden of $S$. aureus, they concomitantly acquired oxidase-positive gram-negative bacilli in the home washing machine. These bacteria were nearly eliminated by tumble drying or ironing. Similarly, investigators found that recently laundered clothing material acquired gram-negative bacteria from the washing ma- 
chine, which were subsequently eliminated by ironing. Another in vitro study in the United Kingdom compared the reduction of microorganisms on artificially inoculated nurses' uniform material after washing at various temperatures as well as with and without detergents. Washing uniforms contaminated with MRSA and Acinetobacter species at a temperature of $60^{\circ} \mathrm{C}$, with or without detergent, achieved at least a $7-\log$ reduction in the bacterial burden of both microorganisms. ${ }^{46}$ There is no robust evidence that centralized industrial laundering decontaminates clothing more effectively than home laundering. ${ }^{43}$

F. Footwear: Although restrictions on HCP footwear are influenced by a desire to meet patients' preferences for appropriate attire, ${ }^{10,14,15}$ most are driven by concerns for HCP safety. ${ }^{47-50}$ Studies have found that wearing of shoes with closed toes, low heels, and nonskid soles can decrease the risk of exposure to blood or other potentially infectious material, ${ }^{47,48,50,51}$ sharps injuries, ${ }^{48,50,52}$ slipping, ${ }^{50}$ and musculoskeletal disorders. ${ }^{49}$

Casual, open footwear, such as sandals, clogs, and foam clogs, potentially expose feet to injury from dropped contaminated sharps and exposure to chemicals in healthcare facilities. A comparison of needlestick injury surveillance data from the standardized Exposure Prevention Information Network program revealed a higher proportion of hollow-bore needle injuries to the feet of Japanese HCP, with $1.5 \%$ of 16,154 total injuries compared with $0.6 \%$ of 9,457 total injuries for US HCP $(2.5$ times higher; $P<$ $.001) .^{48}$ Although multiple factors were linked to these injuries, one included the common practice in Japan to remove outdoor shoes and replace them with open-toed slippers on hospital entry.

Footwear is an area of increased concern in the OR. The Association of periOperative Registered Nurses (AORN) recommends that OR footwear have closed toes as well as backs, low heels, and nonskid soles to prevent slipping. ${ }^{50}$ The US Occupational Safety and Health Administration (OSHA) requires the use of protective shoes in areas where there is a danger of foot injuries from falling objects or objects piercing the soles. ${ }^{47}$ One study that measured the resistance of shoes to penetration by scalpels showed that of the 15 pairs of shoes studied, only 6 were made of material that was sharp resistant, including sneaker suede, suede with inner mesh lining, leather with inner canvas lining, nonpliable leather, rubber with inner leather lining, and thicker rubber. ${ }^{52}$ The OSHA bloodborne pathogens standard mandates that employers determine the workplace settings in which gross contamination with blood or body fluids is expected, such as the OR, and to provide protective shoe coverings in those settings. ${ }^{47,48,50,51}$ Shoe covers are not meant to prevent transmission of bacteria from the OR floor; in fact, preliminary data show that the OR floor may play a dynamic role in the horizontal transmission of bacteria due to frequent floor contact of objects that then directly touch the patient's body (eg, intravenous tubing, electrocardiogram leads). ${ }^{53}$

When HCP safety concerns or patient preference conflict with a HCP's desire for fashion, a facility's dress code can be the arbiter of footwear. OSHA allows employers to make such dress code determinations without regard to a worker's potential exposure to blood, other potentially infectious materials, or other recognized hazards.

\section{Outbreaks Linked to HCP Apparel}

Wright et $\mathrm{al}^{54}$ reported an outbreak of Gordonia potentially linked to HCP apparel. In this report, postoperative sternal wound infections with Gordonia bronchialis in 3 patients were linked to a nurse anesthetist. Gordonia was isolated from the HCP's scrubs, axillae, hands, and purse and from multiple sites on the HCP's roommate.

\section{Studies from Developing Countries}

In Nigeria, factors identified increasing the likelihood of bacterial contamination of white coats included daily laundering and use limited to patient care rather than nonclinical duties. ${ }^{55}$ In India, ${ }^{56}$ medical students' white coats were assessed for bacterial contamination, paired with surveys about laundering habits and attitudes toward white coats. Coats were contaminated most frequently with $S$. aureus, followed by Pseudomonas species and coagulase-negative staphylococci. A similar trial of white coats used by staff in a rural dental clinic also revealed predominantly gram-positive contamination. ${ }^{57}$

\section{Hospital Policies Addressing HCP Attire}

We reviewed and compared policies related to HCP attire from 7 large teaching hospitals or health systems. In general, policies could be categorized into 2 groups:

A. General appearance and dress of all employees

B. Standards for HCP working in sterile or procedure-based environments (OR, central processing, procedure areas, etc)

Policies were evaluated for the following elements:

A. Recommended clothing (eg, requirement for white coats, designated uniforms) or other options (eg, BBE)

B. Guidance regarding scrubs

C. Use of name tags

D. Wearing of ties

E. Requirements for laundering or change of clothing

F. Footwear and nonapparel items worn or carried by HCP

G. Personal protective equipment

All institutions' human resources policies outlined general appearance or dress code requirements for professional standards of business attire; however, institutions varied in jobspecific policies and for the most part did not address more specific attire requirements except for OR-related activities. Few institutional policies included enforcement provisions. The institutions that required accountability varied from de- 


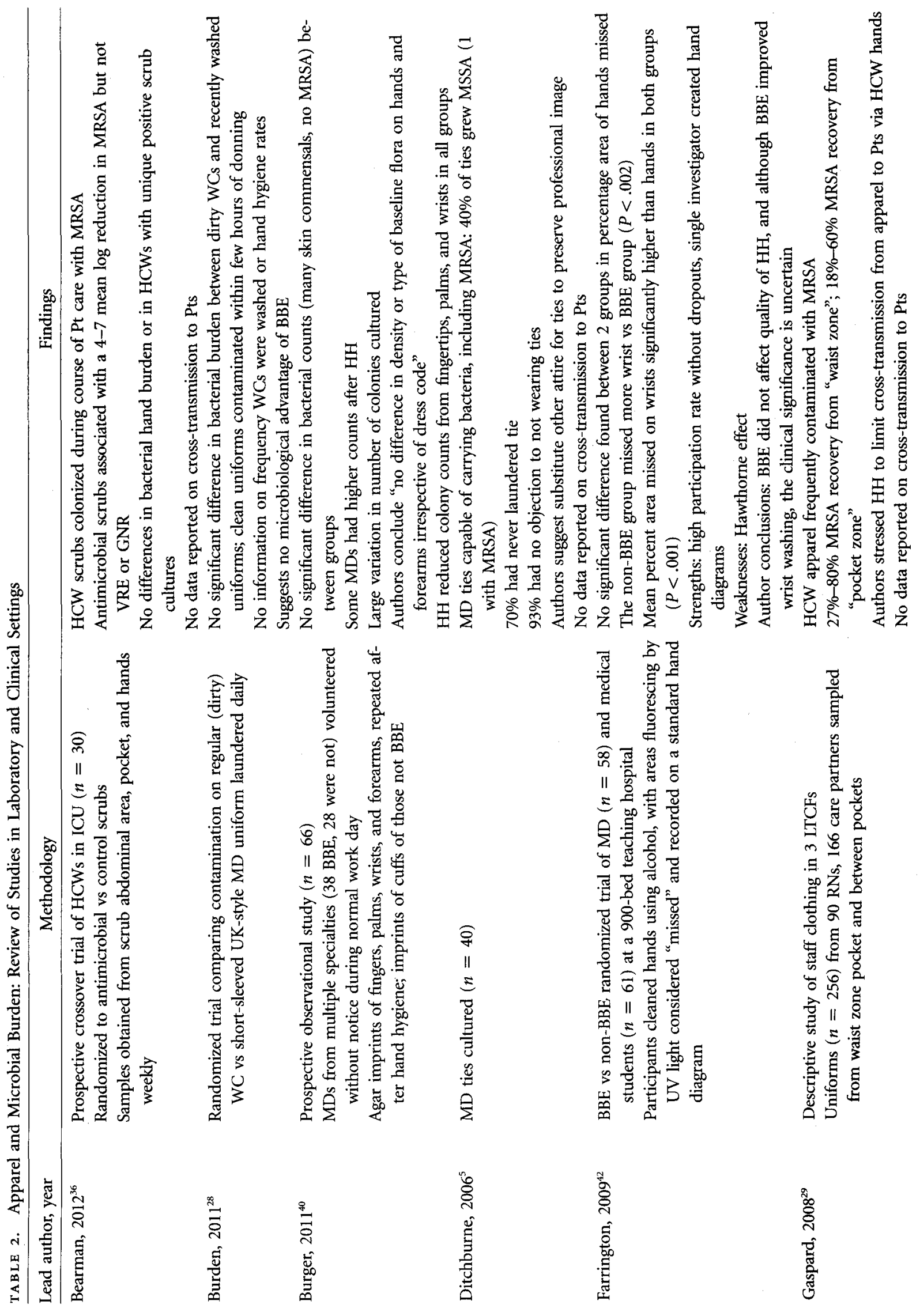




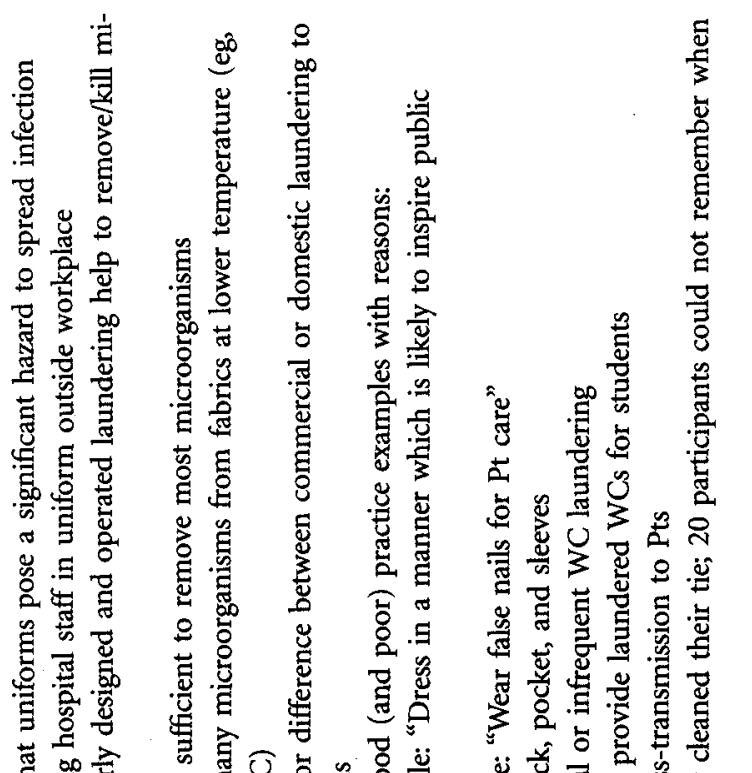

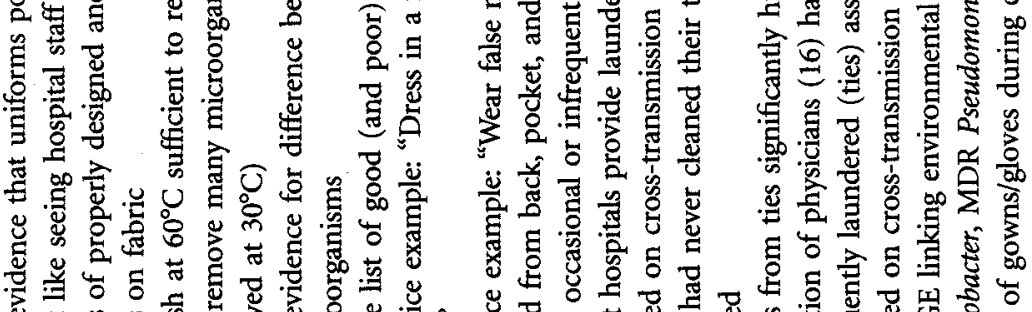

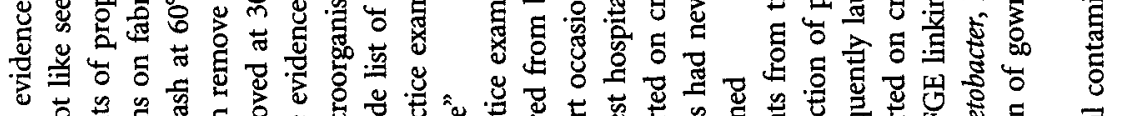

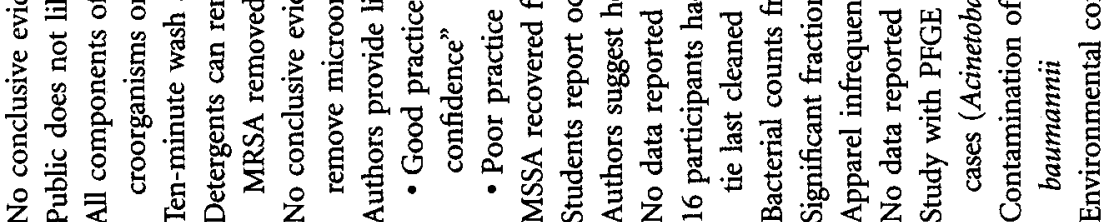

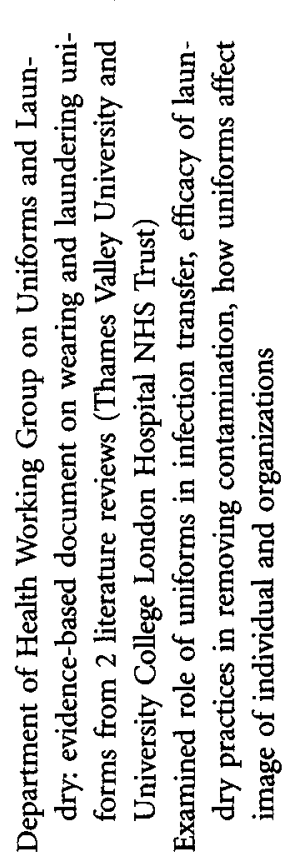

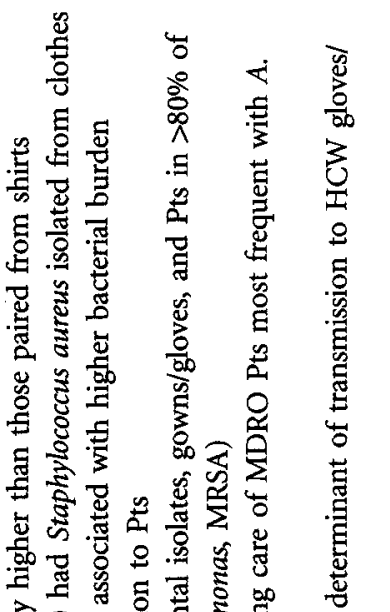

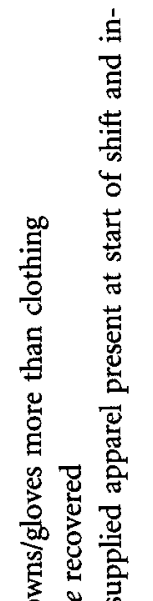

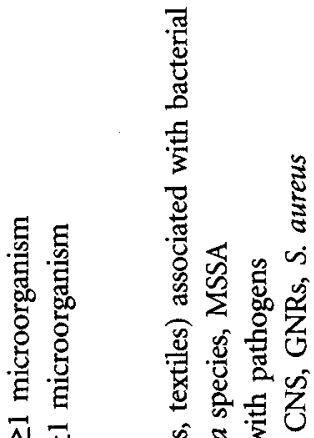

ता $\bar{\lambda}$ के 苟

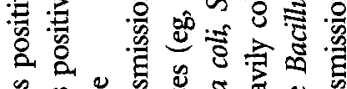

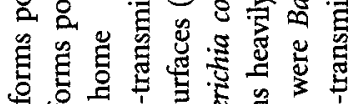

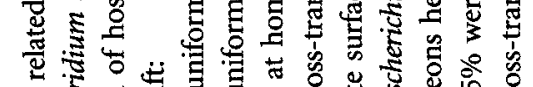

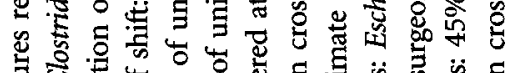

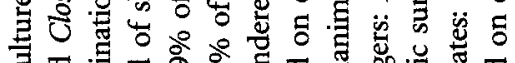

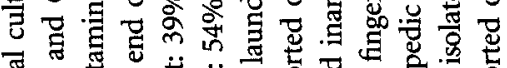

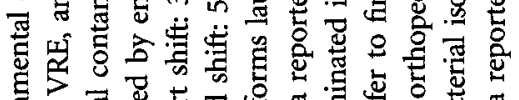

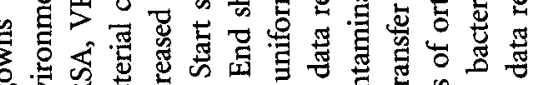

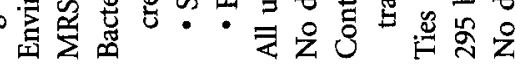

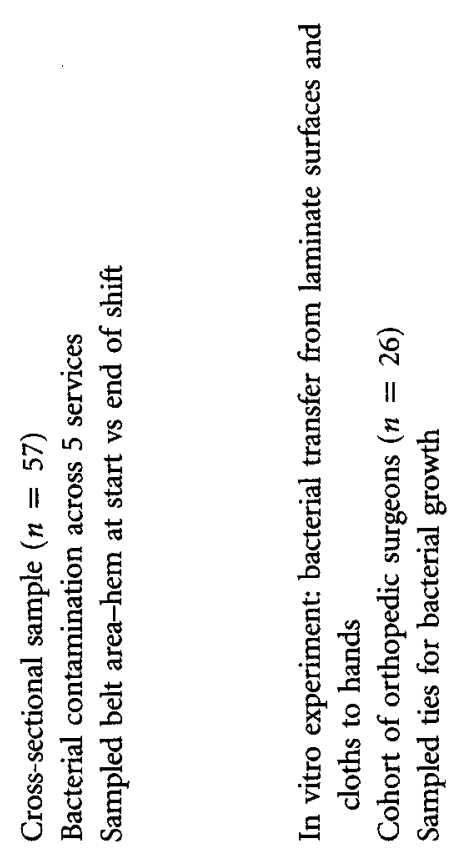

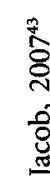

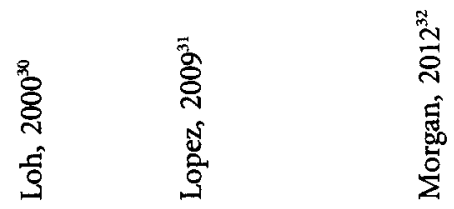

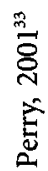

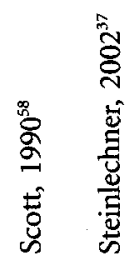







tailing the supervisor's administrative responsibilities to more specific consequences for employee noncompliance.

Three institutions recommended clothing (such as colorcoded attire) for specific types of caregivers (eg, nurses, nurses' assistants, etc). Policies specific to clinical personnel were most frequently related to surgical attire, including scrubs, use of masks, head covers, and footwear in restricted and semirestricted areas and surgical suites, and to central processing, as consistent with AORN standards. Scrubs were universally provided by the hospital in these settings. Laundering policies clearly indicated that laundering of hospitalprovided scrubs was to be performed by the hospital or at a hospital-accredited facility. Use of masks, head covers, footwear, and jewelry were generally consistent with AORN standards.

Excluding surgical attire, only one institution provided guidance specific to physicians, outlining a recommendation for BBE attire during patient care. This policy specified not to use white coats, neckties, long sleeves, wristwatches, or bracelets. Institutional policies also varied in recommendations for laundering and change of clothing other than for surgical attire. No specific guidance was issued for other uniforms, other than cleanliness and absence of visible soiling; however, one institution referred to infection control specifications for maintenance of clothing. Guidance regarding frequency of clothing change was variable for scrubs, from nonspecific requirements (eg, wearing freshly laundered surgical attire on entry to restricted/semirestricted areas) to specific requirements (clean scrubs once per shift to once daily and if visibly soiled). In addition, most policies included instructions for HCP to remove scrubs and change into street clothes either at the end of the shift or when leaving the hospital or connected buildings.

\section{Survey Results}

A total of 337 SHEA members and members of the SHEA Research Network (21.7\% response of 1,550 members) responded to the survey regarding their institutions' policies for HCP attire. The majority of respondents worked at hospitals (91\%); additional facilities included freestanding children's hospitals (4\%), freestanding clinics (1\%), and other facility types $(5 \%)$, such as long-term acute care hospitals, multihospital systems, short-term nursing facilities, and rehabilitation hospitals (rounding of numbers accounts for the sum of percentages being greater than 100). The majority of responses were from either university/teaching hospitals $(39 \%)$ or university/teaching-affiliated hospitals $(28 \%)$. We received additional responses from nonteaching hospitals (24\%), Veterans Affairs hospitals (3\%), specialty hospitals $(2 \%)$, and miscellaneous facilities (4\%).

Enforcement of $\mathrm{HCP}$ attire policies was low at $11 \%$. A majority of respondents (65\%) felt that the role of HCP attire in the transmission of pathogens within the healthcare setting was very important or somewhat important.
Only $12 \%$ of facilities encouraged short sleeves, and $7 \%$ enforced or monitored this policy. Pertaining to white coats, only $5 \%$ discouraged their use and, of those that did, $13 \%$ enforced or monitored this policy. For watches and jewelry, $20 \%$ of facilities had a policy encouraging their removal. A majority of respondents $(61 \%)$ stated that their facility did not have policies regarding scrubs, scrub-like uniforms, or white coats in nonclinical areas. Thirty-one percent responded that their hospital policy stated that scrubs must be removed before leaving the hospital, while $13 \%$ stated that scrubs should not be worn in nonclinical areas. Neckties were discouraged in $8 \%$ of facilities, but none monitored or enforced this policy.

Although $43 \%$ of respondents stated that their hospitals issued scrubs or uniforms, only $36 \%$ of facilities actually laundered scrubs or uniforms. A small number of hospitals provided any type of guidance on home laundering: $13 \%$ provided specific policies regarding home laundering, while $38 \%$ did not.

In contrast to other items of HCP attire, half of facilities required specific types of footwear, and $63 \%$ enforced and/ or monitored this policy.

\section{DISCUSSION}

Overall, patients express preferences for certain types of attire, with most surveys indicating a preference for formal attire, including a preference for a white coat. However, patient comfort, satisfaction, trust, and confidence in their physicians is unlikely to be affected by the practitioner's attire choice. The ability to identify a HCP was consistently reported as one of the most important attributes of HCP attire in studies. This was particularly true in studies that evaluated the effect of attire of actual physicians on patient satisfaction in a realworld setting rather than those assessing the influence of physician attire on patient satisfaction in the abstract. Patients generally did not perceive white coats, formal attire, or ties as posing infection risks; however, when informed of potential risks associated with certain types of attire, patients were willing to change their preferences for physician attire. ${ }^{11,18}$

Data from convenience-sample surveys and prospective studies confirm that contamination occurs for all types of HCP apparel, including scrubs, neckties, and white coats, with pathogens such as S. aureus, MRSA, VRE, and gram-negative bacilli. HCP apparel can hypothetically serve as a vector for pathogen cross-transmission in healthcare settings; however, no clinical data yet exist to define the impact of HCP apparel on transmission. The benefit of institutional laundering of $H C P$ scrubs versus home laundering for non-OR use remains unproven. A BBE approach is in effect in the United Kingdom for inpatient care; this strategy may enhance hand hygiene to the level of the wrist, but its impact on HAI rates remains unknown.

Hospital policies regarding $\mathrm{HCP}$ attire were generally consistent in their approach to surgical attire; however, general 
dress code policies varied from guidance regarding formal attire to use of job-specific uniforms. Laundering and change of clothing was also not consistently addressed other than for surgical attire. Finally, accountability for compliance with the attire policies by HCP and supervisors was not routinely included in the policies.

\section{AREAS FOR FUTURE RESEARCH}

I. Determine the role played by HCP attire in the horizontal transmission of nosocomial pathogens and its impact on the burden of HAIs.

II. Evaluate the impact of antimicrobial fabrics on the bacterial burden of HCP attire, horizontal transmission of pathogens, and HAIs. Concomitantly, a cost-benefit analysis should be conducted to determine the financial merit of this approach.

III. Establish the effect of a BBE policy on both the horizontal transmission of nosocomial pathogens and the incidence of HAIs.

IV. Explore the behavioral determinants of laundering practices among HCP regarding different apparel and examine potential interventions to decrease barriers and improve compliance with laundering.

V. Examine the impact of not wearing white coats on patients' and colleagues' perceptions of professionalism on the basis of HCP variables (eg, gender, age).

VI. Evaluate the impact of compliance with hand hygiene and standard precautions on contamination of $\mathrm{HCP}$ apparel.

\section{ACKNOWLEDGMENTS}

Financial support. This study was supported in part by the SHEA Research Network.

Potential conflicts of interest. G.B. reports receiving grants from Pfizer, Cardinal Health, BioVigil, and Vestagen Technical Textiles. M.E.R. reports receiving research grants/contracts from $3 \mathrm{M}$ and having an advisory/consultant role with $3 \mathrm{M}$, Ariste, Care Fusion, and Mölnlycke. All other authors report no conflicts of interest relevant to this article.

Address correspondence to Gonzalo Bearman MD, MPH, Virginia Commonwealth University, Internal Medicine, Richmond, VA 23298 (gbearman $@$ @cvh-vcu.edu).

\section{REFERENCES}

1. Ardolino A, Williams LA, Crook TB, Taylor HP. Bare below the elbows: what do patients think? J Hosp Infect 2009;71:291-293.

2. Baevsky RH, Fisher AL, Smithline HA, Salzberg MR. The influence of physician attire on patient satisfaction. Acad Emerg Med 1998;5:82-84.

3. Bond L, Clamp PJ, Gray K, Van DV. Patients' perceptions of doctors' clothing: should we really be "bare below the elbow"? $J$ Laryngol Otol 2010;124:963-966.

4. Cha A, Hecht BR, Nelson K, Hopkins MP. Resident physician attire: does it make a difference to our patients? Am J Obstet Gynecol 2004;190:1484-1488.

5. Ditchburne I. Should doctors wear ties? J Hosp Infect 2006;63: 227-228.

6. Fischer RL, Hansen CE, Hunter RL, Veloski JJ. Does physician attire influence patient satisfaction in an outpatient obstetrics and gynecology setting? Am J Obstet Gynecol 2007;196:186e.1$186 \mathrm{e} .5$.

7. Gallagher J, Waldron LF, Stack J, Barragry J. Dress and address: patient preferences regarding doctor's style of dress and patient interaction. Ir Med J 2008;101:211-213.

8. Gherardi G, Cameron J, West A, Crossley M. Are we dressed to impress? a descriptive survey assessing patients' preference of doctors' attire in the hospital setting. Clin Med 2009;9:519-524.

9. Gonzalez del Rey JA, Paul RI. Preferences of parents for pediatric emergency physicians' attire. Pediatr Emerg Care 1995;11:361364.

10. Hennessy N, Harrison DA, Aitkenhead AR. The effect of the anaesthetist's attire on patient attitudes: the influence of dress on patient perception of the anaesthetist's prestige. Anaesthesia 1993;48:219-222.

11. Hueston WJ, Carek SM. Patients' preference for physician attire: a survey of patients in family medicine training practices. Fam Med 2011;43:643-647.

12. Ikusaka M, Kamegai M, Sunaga T, et al. Patients' attitude toward consultations by a physician without a white coat in Japan. Intern Med 1999;38:533-536.

13. Li SF, Haber M. Patient attitudes toward emergency physician attire. J Emerg Med 2005;29:1-3.

14. Major K, Hayase Y, Balderrama D, Lefor AT. Attitudes regarding surgeons' attire. Am J Surg 2005;190:103-106.

15. Matsui D, Cho M, Rieder MJ. Physicians' attire as perceived by young children and their parents: the myth of the white coat syndrome. Pediatr Emerg Care 1998;14:198-201.

16. McKinstry B, Wang JX. Putting on the style: what patients think of the way their doctor dresses. Br J Gen Pract 1991;41:270, 275278.

17. Mistry D, Tahmassebi JF. Children's and parents' attitudes towards dentists' attire. Eur Arch Paediatr Dent 2009;10:237-240.

18. Monkhouse SJ, Collis SA, Dunn JJ, Bunni J. Patients' attitudes to surgical dress: a descriptive study in a district general hospital. $J$ Hosp Infect 2008;69:408-409.

19. Nair BR, Attia JR, Mears SR, Hitchcock KI. Evidence-based physicians' dressing: a crossover trial. Med J Aust 2002;177:681682.

20. Niederhauser A, Turner MD, Chauhan SP, Magann EF, Morrison JC. Physician attire in the military setting: does it make a difference to our patients? Mil Med 2009;174:817-820.

21. Palazzo S, Hocken DB. Patients' perspectives on how doctors dress. J Hosp Infect 2010;74:30-34.

22. Rehman SU, Nietert PJ, Cope DW, Kilpatrick AO. What to wear today? effect of doctor's attire on the trust and confidence of patients. Am J Med 2005;1 18:1279-1286.

23. Shelton CL, Raistrick C, Warburton K, Siddiqui KH. Can changes in clinical attire reduce likelihood of cross-infection without jeopardising the doctor-patient relationship? J Hosp Infect 2010;74:22-29.

24. Baxter JA, Dale O, Morritt A, Pollock JC. Bare below the elbows: professionalism vs infection risk. Bull $R$ Coll Surg Engl 2010;92: 248-251. 
25. Toquero L, Abournarzouk O, Owers $C$, Chiang R, Thiagarajah $S$, Amin S. Bare below the elbows-the patient's perspective. WebmedCentral Qual Patient Saf 2011;2:WMC001401.

26. Garvin K, Ali F, Neradelik M, Pottinger P. Attitudes regarding the safety of healthcare provider attire. Presented at IDWeek, October 8-12, 2012, Philadelphia, PA. Poster 455.

27. Munoz-Price LS, Arheart KL, Lubarsky DA, Birnbach DJ. Differential laundering practices of white coats and scrubs among health care professionals. Am J Infect Control 2013;41:565-567.

28. Burden M, Cervantes L, Weed D, Keniston A, Price CS, Albert RK. Newly cleaned physician uniforms and infrequently washed white coats have similar rates of bacterial contamination after an 8-hour workday: a randomized controlled trial. J Hosp Med 2011;6:177-182.

29. Gaspard P, Eschbach E, Gunther D, Gayet S, Bertrand X, Talon D. Meticillin-resistant Staphylococcus aureus contamination of healthcare workers' uniforms in long-term care facilities. J Hosp Infect 2009;71:170-175.

30. Loh W, Ng VV, Holton J. Bacterial flora on the white coats of medical students. J Hosp Infect 2000;45:65-68.

31. Lopez PJ, Ron O, Parthasarathy P, Soothill J, Spitz L. Bacterial counts from hospital doctors' ties are higher than those from shirts. Am J Infect Control 2009;37:79-80.

32. Morgan DJ, Rogawski E, Thom KA, et al. Transfer of multidrugresistant bacteria to healthcare workers' gloves and gowns after patient contact increases with environmental contamination. Crit Care Med 2012;40:1045-1051.

33. Perry C, Marshall R, Jones E. Bacterial contamination of uniforms. J Hosp Infect 2001;48:238-241.

34. Treakle AM, Thom KA, Furuno JP, Strauss SM, Harris AD, Perencevich EN. Bacterial contamination of health care workers' white coats. Am I Infect Control 2009;37:101-105.

35. Wong D, Nye K, Hollis P. Microbial flora on doctors' white coats. BMJ 1991;303:1602-1604.

36. Bearman GM, Rosato A, Elam $\mathrm{K}$, et al. A crossover trial of antimicrobial scrubs to reduce methicillin-resistant Staphylococcus aureus burden on healthcare worker apparel. Infect Control Hosp Epidemiol 2012;33:268-275.

37. Steinlechner C, Wilding G, Cumberland N. Microbes on ties: do they correlate with wound infection? Bull R Coll Surg Engl 2002:84:307-309.

38. Wiener-Well Y, Galuty M, Rudensky B, Schlesinger Y, Attias D, Yinnon AM. Nursing and physician attire as possible source of nosocomial infections. Am J Infect Control 2011;39:555-559.

39. Munoz-Price LS, Arheart KL, Mills JP, et al. Associations between bacterial contamination of health care workers' hands and contamination of white coats and scrubs. Am J Infect Control 2012;40:e245-e248.

40. Burger A, Wijewardena C, Clayson S, Greatorex RA. Bare below elbows: does this policy affect handwashing efficacy and reduce bacterial colonisation? Ann R Coll Surg Engl 2011;93:13-16.

41. Willis-Owen CA, Subramanian P, Kumari P, Houlihan-Burne D. Effects of "bare below the elbows" policy on hand contamination of 92 hospital doctors in a district general hospital. $J$ Hosp Infect 2010;75:116-119.
42. Farrington RM, Rabindran J, Crocker G, Ali R, Pollard N, Dalton HR. "Bare below the elbows" and quality of hand washing: a randomised comparison study. J Hosp Infect 2010;74:86-88.

43. Jacob G. Uniforms and Workwear: An Evidence Base for Developing Local Policy. National Health Service Department of Health Policy, 2007.

44. Blaser MJ, Smith PF, Cody HJ, Wang WL, LaForce FM. Killing of fabric-associated bacteria in hospital laundry by low-temperature washing. I Infect Dis 1984;149:48-57.

45. Patel SN, Murray-Leonard J, Wilson AP. Laundering of hospital staff uniforms at home. J Hosp Infect 2006;62:89-93.

46. Lakdawala N, Pham J, Shah M, Holton J. Effectiveness of lowtemperature domestic laundry on the decontamination of healthcare workers' uniforms. Infect Control Hosp Epidemiol 2011;32:1103-1108.

47. Occupational Safety and Health Administration Bloodborne Pathogens Standard, 29 CFR 1910.1030 (2013).

48. Yoshikawa T, Kidouchi K, Kimura S, Okubo T, Perry J, Jagger J. Needlestick injuries to the feet of Japanese healthcare workers: a culture-specific exposure risk. Infect Control Hosp Epidemiol 2007;28:215-218.

49. Chiu MC, Wang MJ. Professional footwear evaluation for clinical nurses. Appl Ergon 2007;38:133-141.

50. Blanchard J. Wearing shoe covers and appropriate footwear in the OR. AORN J 2010;92:228-229.

51. Barr J, Siegel D. Dangers of dermatologic surgery: protect your feet. Dermatol Surg 2004;30:1495-1497.

52. Watt AM, Patkin M, Sinnott MJ, Black RJ, Maddern GJ. Scalpel safety in the operative setting: a systematic review. Surgery 2010; 147:98-106.

53. Munoz-Price LS, Birnbach DJ, Lubarsky DA, et al. Decreasing operating room environmental pathogen contamination through improved cleaning practice. Infect Control Hosp Epidemiol 2012;33:897-904.

54. Wright SN, Gerry JS, Busowski MT, et al. Gordonia bronchialis sternal wound infection in 3 patients following open heart surgery: intraoperative transmission from a healthcare worker. Infect Control Hosp Epidemiol 2012;33:1238-1241.

55. Uneke CJ, Ijeoma PA. The potential for nosocomial infection transmission by white coats used by physicians in Nigeria: implications for improved patient-safety initiatives. World Health Popul 2010;11:44-54.

56. Banu A, Anand $M$, Nagi N. White coats as a vehicle for bacterial dissemination. J Clin Diagn Res 2012;6:1381-1384.

57. Priya $\mathrm{H}$, Acharya $\mathrm{S}$, Bhat $\mathrm{M}$, Ballal $\mathrm{M}$. Microbial contamination of the white coats of dental staff in the clinical setting. J Dent Res Dent Clin Dent Prospects 2009;3:136-140.

58. Scott E, Bloomfield SF. The survival and transfer of microbial contamination via cloths, hands and utensils. J Appl Bacteriol 1990;68:271-278.

59. Wilson IA, Loveday HP, Hoffman PN, Pratt RJ. Uniform: an evidence review of the microbiological significance of uniforms and uniform policy in the prevention and control of healthcareassociated infections. Report to the Department of Health (England). J Hosp Infect 2007;66:301-307. 